\title{
Recursos educacionais abertos e direitos autorais: análise de sítios educacionais brasileiros
}

ALICE AQUINO ZANIN

Universidade de São Paulo, São Paulo, SP, Brasil

RESUMO

O movimento acesso aberto desencadeou o aumento do número de repositórios e bibliotecas que disponibilizam recursos educacionais abertos. $\mathrm{O}$ termo "aberto" leva à reflexão de quais são os direitos autorais que envolvem esse conceito e se há informação aos usuários de tais direitos. O objetivo desta pesquisa é analisar as informações fornecidas aos usuários nos repositórios educacionais brasileiros quanto aos direitos autorais e licenças de uso. Concluiu-se que não foram disponibilizadas informações mínimas aos internautas na maioria dos repositórios analisados. $\mathrm{O}$ acesso à informação permite a realização de escolhas mais qualificadas pelo usuário para o exercício de seus direitos, e a falha na informação da matéria em questão pode gerar a ofensa aos direitos do autor.

PALAVRAS-CHAVE

recursos educacionais abertos; direitos autorais; direito à informação; licença de uso. 


\section{OPEN EDUCATIONAL RESOURCES AND COPYRIGHT: ANALYSIS OF BRAZILIAN WEB SITES}

\section{ABSTRACT}

The open access triggered the increase in the number of repositories and libraries that offer open educational resources. The word "open" leads to a reflection of what are the copyrights involving this concept, and if users are informed about these rights. The objective of this research is to analyze the information provided to users about copyright and licenses, in Brazilian educational repositories. It was concluded that minimal information was not made available to Internet users in the majority of the analyzed repositories. Access to information allows for more qualified user's choices to exercise their rights, and the failure of the subject matter information may cause offense to the author's rights.

\section{KEYWORDS}

open educational resources; copyright; right to information; use license.

\section{RECURSOS EDUCATIVOS ABIERTOS Y DERECHO DE AUTOR: ANÁLISIS DE SITIOS EDUCATIVOS BRASILEÑOS}

\section{RESUMEN}

El movimiento de acceso abierto provocó el aumento en el número de repositórios y bibliotecas que ofrecen recursos educativos abiertos. El término "abierto" lleva a la reflexión de lo que el derecho de autor implica en este concepto, y si los usuarios son informados acerca de estos derechos. El objetivo de esta investigación es analizar la información ofrecida a los usuarios en los repositorios educativos brasileños. Se concluyó que no se puso a disposición de los usuarios de Internet la información adecuada, en la mayoría de los repositorios analizados. El acceso a la información permite la realización de opciones más cualificadas por los usuarios para el ejercicio de sus derechos, y falla en la información puede causar ofensa a los derechos del autor. 


\section{INTRODUÇÃO}

O avanço das tecnologias de informação e o crescente uso da internet possibilitaram o surgimento de um novo processo de comunicação (Assis, 2013; Rangel et al., 2015) e transformaram as estratégias de ensino e aprendizagem (Silva, Café e Catapan, 2010). Visando atender à demanda educativa, surgiu o movimento acesso aberto (open access, em inglês), que defende o acesso aberto à literatura e outros conteúdos de caráter acadêmico, científico ou técnico, sem restrições, online, livre de qualquer cobrança de taxa ou necessidade de assinatura, a qualquer pessoa, para que se possa ler, fazer download, copiar, distribuir, imprimir ou pesquisar (Müller, 2012).

Os recursos educacionais abertos (REA) estão alinhados com esse movimento de aprendizagem aberta, colaborativa e que utiliza intensivamente recursos tecnológicos para estimular a autonomia e a emancipação do aprendente (Silva, Café e Catapan, 2010).

\section{RECURSOS EDUCACIONAIS ABERTOS}

Os REA, ${ }^{1}$ definidos de forma objetiva, são todos os materiais de ensino, aprendizagem ou pesquisa em domínio público ou publicados sob uma licença aberta que permite o seu uso de forma legal. O objetivo da criação dos REA é a produção de conteúdo sem ideia proprietária, mas sim de bem comum, visando à educação igualitária mundial por meio da colaboração e do compartilhamento do conhecimento de forma gratuita e sem restrições, ou com poucas restrições, de direitos autorais.

Os REA são importantes instrumentos em processos educacionais presenciais e a distância. Estão vinculados à colaboração, ao compartilhamento e ao desenvolvimento da equidade da educação no mundo.

REA é, mais que tudo, um movimento para que pessoas tenham consciência crítica sobre o seu papel em uma sociedade cada vez mais mediada por recursos digitais. Para que tenham clareza de como, quando, e por que compartilhar conhecimento e recursos. De fomentar o compartilhamento de boas ideias, pensar em novas maneiras de fazer uso de recursos educacionais, novas práticas didáticas e de encorajar a troca de experiências entre alunos e professores, reduzindo barreiras legais ou empecilhos técnicos. (Morais et al. apud Educação Aberta, 2011)

A Organização das Nações Unidas para a Educação, a Ciência e a Cultura (UNESCO), no relatório Educação para Todos, em 2007, afirmou que a disponibilização de escolas, professores, livros e equipamentos é fator-chave para a melhoria na qualidade de todo o sistema educacional. Nota-se que a disponibilidade dos materiais educacionais é primordial para que seja promovida uma educação gratuita e de qualidade, principalmente em países em desenvolvimento nos quais o

1 O termo REA ou open educational resources (OER), em inglês, foi introduzido no Primeiro Fórum Global em REA, em 2002, realizado pela UNESCO. 
governo não distribui gratuitamente livros aos alunos, sendo estes subsidiados pelas famílias. Para solucionar o problema de acesso a materiais de ensino, é proposto o movimento aberto, que utiliza meios alternativos de distribuição e elaboração de novos materiais de qualidade e de maneira gratuita.

Segundo a Declaração da UNESCO (2012), os REA são materiais ou objetos de aprendizagem, ensino, extensão e pesquisa em qualquer suporte ou mídia, de natureza eletrônica multimodal e de hipermediação (texto, som, imagem), que estão sob domínio público ou licenciados de maneira aberta, permitindo que sejam utilizados, distribuídos, compartilhados ou adaptados por qualquer pessoa. Podem abranger cursos completos, partes de cursos, módulos, livros didáticos, artigos de pesquisa, vídeos, software e qualquer outra ferramenta, material ou técnica que possa apoiar o acesso ao conhecimento.

Com base na referida declaração, foram resumidas de forma didática quatro ações/liberdades, também chamadas de “4R" para utilização dos REA:

1. Reutilizar: liberdade de utilizar o material em sua forma original ou modificada;

2. Revisar: liberdade de adaptar, ajustar, modificar, atualizar, traduzir ou alterar;

3. Remixar: liberdade de combinar o material original ou revisado com outro para criar algo novo; e

4. Redistribuir: liberdade de compartilhar cópias do conteúdo original, das revisões ou do "remix". (Recursos Educacionais Abertos, s/d.)

Há autores (Araya e Vidotti, 2009, Pinto et al., 2011; Recursos Educacionais Abertos, s/d.) que entendem que somente pode ser considerado REA quando o recurso dispõe de uma licença que possibilite as quatro liberdades, porém não há consenso entre os estudiosos. A licença aberta pressupõe que o material de ensino está disponibilizado de forma gratuita, com pouca ou nenhuma restrição de direitos autorais, seja técnica ou legal, e que é livre para ser utilizado, adaptado e distribuído. Ou seja, é aberto porque é livre e porque permite outras formas de uso, outras produções, a partir do processo de compartilhamento, sem a necessidade de pedir permissão para utilização do recurso ao autor ou à editora, desde que respeitados os termos da licença. Parte-se do pressuposto de que há material de qualidade disponível, que pode ser modificado, adaptado à realidade do usuário ou atualizado, e, dessa forma, o conhecimento é expandido com economia de tempo e dinheiro. Economiza-se tempo, pois os autores trabalham em comunidade e não precisam partir do zero, mas utilizam o que já está na web. E economiza-se dinheiro porque o material ou software, por exemplo, é de uso livre, não necessita ser pago/comprado para ser utilizado.

A utilização do REA deve atender, portanto, a dois critérios. Primeiro, deve ser utilizado de acordo com o tipo de licença de uso fornecida pelo autor do material, ou seja, quanto mais aberta a licença maior a gama de possibilidades de seu uso e menores as limitações. E, em segundo lugar, a utilização do objeto de aprendizagem implica o conhecimento de suas características, potencialidades e deficiências, para que seja aplicado de forma apropriada para atingir o objetivo de aprendizagem requerido. 
Todas as informações do recurso de aprendizagem devem estar disponíveis, de forma acessível, para que o usuário esteja consciente tanto das potencialidades do REA como da licença de uso, e o utilize adequadamente para que seja atingido o objetivo educacional sem violação dos direitos do autor.

\section{DIREITO À INFORMAÇÃO}

O usuário deve ser informado de maneira clara e objetiva sobre seus direitos e obrigações a respeito dos direitos do autor, do tipo de licença de uso, das permissões e restrições no uso do objeto de aprendizagem, sob pena de, por falta de informação, infringir esses direitos, seguindo a premissa de que tudo que está na rede é livre para uso indiscriminado.

A informação visa dotar o usuário de elementos objetivos de realidade que lhe permitam conhecer os produtos e serviços e exercer suas escolhas (Lôbo, 2005). Canela e Solano (2009, p. 11) ensinam que

as múltiplas relações sociais que caracterizam a vida em uma sociedade democrática são marcadas por um elemento fundamental: a necessidade de o indivíduo fazer escolhas. Essas escolhas serão tão mais próximas do ponto ótimo almejado pelo indivíduo quanto mais informações ele ou ela detiver sobre as opções, os caminhos, as alternativas e as possibilidades disponíveis. O pressuposto da ideia é que a tomada de decisões bem informadas beneficiará o indivíduo [...].

Além de permitir a realização de escolhas mais qualificadas, o acesso à informação é central, ainda na perspectiva individual, para a consecução de um conjunto de direitos. Em outras palavras, o acesso à informação é um direito que antecede outros.

A Constituição Brasileira, em seu inciso XIV, artigo 5०, determina que "é assegurado a todos o acesso à informação" (Brasil, 1988). O direito à informação remete ao dever de informar daquele que detém o domínio das informações. Cumpre-se esse dever quando a informação recebida pelo usuário preenche os requisitos de adequação, suficiência e veracidade. A adequação relaciona-se com os meios de informação utilizados e com o respectivo conteúdo. Os organizadores do site devem prover os meios que permitam e facilitem o conhecimento e a compreensão da informação. Os signos empregados (imagens, palavras, sons) devem ser claros e precisos, estimulantes do conhecimento e da compreensão. A suficiência relaciona-se com a completude e integralidade da informação (Lôbo, 2005). Já a veracidade explica-se por si só.

O dever de informar tem raiz histórica na boa-fé (Lôbo, 2005), que é elemento fundamental dos contratos. A relação entre o usuário do material e o autor que o disponibiliza na internet não deixa de ser uma relação contratual, que gera um conjunto de expectativas recíprocas. A boa-fé introduz na relação contratual duas noções fundamentais que impõem um padrão de conduta. A primeira é a imposição de critérios éticos ao cumprimento e à atuação das partes no desenvolvimento da relação. A segunda é a cooperação. Por isso, as partes devem atuar respeitando 
os interesses legítimos um do outro, havendo a imposição de deveres ou mesmo limitações de direitos (Martins, 2008).

$\mathrm{O}$ direito à informação não se confunde com a chamada "sociedade da informação”. Esta identifica o período histórico atual, no qual há a preponderância da informação sobre os meios de produção e distribuição dos bens na sociedade. A revolução informacional reflete-se sobre todas as relações sociais, aprimorando o convívio social e facilitando o acesso à informação. Reflete-se também na criação das leis, como pode ser observado na publicação da lei "Marco Civil da Internet", de 23 de abril de 2014, lei n. 12.965 (Brasil, 2014). Essa lei estabelece princípios, garantias, direitos e deveres para o uso da internet no Brasil e preconiza, em seu artigo $4^{\circ}$, inciso II, que o uso da internet tem como objetivo a promoção "do acesso à informação, ao conhecimento e à participação na vida cultural e na condução dos assuntos públicos". Em seu artigo $7^{\circ}$, inciso VI, assegura aos usuários o direito a "informações claras e completas constantes dos contratos de prestação de serviços". No entanto, a evolução legal não tem acompanhado a evolução das relações sociais, ocorridas em virtude do avanço tecnológico.

No Brasil, os direitos dos autores são regulamentados pela Lei dos Direitos Autorais (LDA), n. 9.610/1998. É notório que essa lei, mesmo com suas alterações posteriores, que inclui a lei n. 12.853/2013, não acompanhou a evolução tecnológica e cultural, porém continua válida e deve ser respeitada. $\mathrm{Na}$ tentativa de equalizar esse descompasso entre legislação e cultura, deve haver um estímulo para a produção de conteúdo aberto, com base em informações claras e precisas tanto aos autores como aos usuários a respeito dos direitos autorais, para que sejam feitas escolhas conscientes de ambas as partes. O autor deverá escolher quais direitos irá dispor para a expansão do conhecimento, e o usuário escolherá o objeto de aprendizagem que apresente as permissões que mais se adequem às suas necessidades, de forma que respeite os direitos autorais ao mesmo tempo em que há a difusão do saber.

\section{DIREITOS AUTORAIS}

Os direitos autorais relacionam-se à educação pelo fato de que todo educador é autor, ou deveria ser, e porque a construção do conhecimento nunca parte do zero, mas é uma evolução do que já existe (Educação Aberta, 2011). A própria definição do que é REA, citada anteriormente, ao tratar do tipo de licença e das liberdades, já demonstra o vínculo indissociável desses recursos com tais direitos.

Direito autoral é o ramo do direito que protege as obras intelectuais ${ }^{2}$ e que regulamenta as relações jurídicas surgidas a partir de sua criação e utilização (Souza e Murakawa, 2014). O direito autoral é dividido em direitos patrimoniais e morais.

Os direitos patrimoniais consistem no direito de o autor fazer uso econômico da sua obra, entre os quais se pode citar o direito de reprodução, distribuição,

2 As obras intelectuais são as criações do espírito expressas por qualquer meio ou fixadas em qualquer suporte, tangível ou intangível, conhecido ou que se invente no futuro (Brasil, 1998, artigo 70). O autor possui, independentemente de registro, o direito exclusivo de utilizar, fruir e dispor de sua obra literária, artística ou científica (Brasil, 1998, artigo 18 c/c 28). 
adaptação, exposição, tradução, execução musical, etc., que podem ser cedidos a terceiros total ou parcialmente por meio de contratos ou licenças (Brasil, 1998, artigos 28 a 44). Esses direitos possuem um prazo, que em regra perduram por setenta anos contados de $1^{\circ}$ de janeiro do ano seguinte ao falecimento do autor (Brasil, 1998, artigo 41). Após esse prazo, as obras "caem" em domínio público, ${ }^{3}$ ou seja, não incidem mais direitos patrimoniais sobre a obra, e, consequentemente, qualquer indivíduo pode utilizá-la livremente, sem a necessidade de qualquer tipo de autorização.

Já os direitos morais são constituídos essencialmente em dois pilares: 1) o direito de paternidade, em que o autor tem não só o direito de ter seu nome vinculado à obra sempre que esta for utilizada, mas também o direito de reivindicar a qualquer tempo a autoria da obra, caso ela tenha sido veiculada em nome de outrem (Morato, 2013); e 2) o direito à integridade da obra, em que o autor tem o direito de se opor à utilização desta em contexto que prejudique sua reputação ou honra (Pinto et al., 2011). Os direitos morais, diferentemente dos patrimoniais, não podem ser renunciados e não podem ser cedidos por meio de licença (Brasil, 1998, artigo 27). Resumindo, sempre que for utilizada uma obra intelectual, no Brasil, qualquer que seja o tipo de licença, ou qualquer que seja a finalidade, deve sempre ser citado o autor da obra.

Há na LDA exceções aos direitos patrimoniais. Essa lei permite o uso de conteúdo para fins educacionais, sem necessidade de autorização, porém de forma muito restritiva. Pode ser observado na leitura de seu artigo 46, inciso III, que "não constitui ofensa aos direitos autorais: a citação em livros, jornais, revistas ou qualquer outro meio de comunicação, de passagens de qualquer obra para fins de estudo, crítica ou polêmica, na medida justificada para o fim a atingir, indicando-se o nome do autor e a origem da obra" (grifos da autora). Ou seja, se a obra não estiver em domínio público ou sob uma licença aberta, somente é permitido o uso de passagens da obra, não sendo permitida a digitalização, cópia integral, distribuição, alteração, "remix" e outras liberdades que caracterizam recursos abertos, que são essenciais na sociedade da educação e informação moderna.

Júnior e Amorim (2012), com o objetivo de orientar os autores/usuários de conteúdos digitais e autorais, sugerem três situações para a proteção de direitos autorais que são: ideais; aceitáveis; e aquelas em que uma autorização se faz imprescindível. Para esses autores, a situação ideal é a utilização de obras que estejam em domínio público, ou que sejam distribuídas sobre licenças abertas respeitando as restrições indicadas. A situação aceitável seria a utilização de partes de obras para fins educacionais e sem fins lucrativos, de acordo com o artigo 46, inciso III (Brasil,

3 As obras em domínio público que podem ser utilizadas livremente respeitando os direitos morais do autor são: a) obras com autorização concedida pelo autor para serem utilizadas livremente; b) obras que excederam o prazo de proteção de setenta anos contados de $1^{\circ}$ de janeiro do ano subsequente ao falecimento do autor, quando há sucessores (Brasil, 1998, artigo 41); c) obras de autores falecidos que não tenham deixado sucessores (Brasil, 1998, artigo 45, inciso I); d) obras de autor desconhecido, ressalvada a proteção legal para os conhecimentos étnicos e tradicionais (Brasil, 1998, artigo 45). 
1998). Já a situação que demanda autorização é o caso do uso de obras completas, que não estejam em domínio público ou não possuam licença aberta.

Infelizmente se observa que na prática, com frequência, as normas legais têm sido desrespeitadas, principalmente no meio acadêmico, pois o acesso a conteúdos por meio da web facilita a cópia e a modificação do conteúdo para posterior publicação na própria internet (Pinto et al., 2011) e não há informação a respeito dos direitos autorais e das licenças de uso.

Caso os direitos patrimoniais e morais não sejam respeitados, haverá sanções (Brasil, 1998, artigos 102 a 107), como indenização e apreensão de exemplares reproduzidos, por exemplo, além da possiblidade de responsabilização por crime de plágio (Brasil, 1940, Código Penal, artigo 184). Porém a proteção de tais direitos deve partir do autor da obra por meio do acionamento do judiciário, pois a estrutura do direito autoral e as instituições que o implementam não tem preparo para lidar com as questões que surgem (Valente, 2013). Tampouco as instituições privadas possuem ferramentas para busca de uso inapropriado dos recursos educacionais ou mecanismos de impedimentos ou de "punições" para os infratores. Os repositórios, por via de regra, nos termos de uso, isentam-se de qualquer responsabilidade em caso de utilização fora ou além do autorizado na licença.

Observa-se ainda que muitas vezes não é possível detectar o infrator, pois a identificação em meio digital é difícil e às vezes impossível, dada a volatilidade e a imaterialidade da informação, mesmo com o desenvolvimento de tecnologias específicas que permitem rastrear a autoria de obras por meio de soluções, como marcas d'água digitais (Júnior, 2012), o que impossibilita, consequentemente, a aplicação de sanções. Fato que causa resistência dos autores e das instituições de ensino em disponibilizar seu material de forma livre na internet.

A inadequação da LDA na sociedade da informação, a impossibilidade de proteção dos direitos autorais pelas instituições, a dificuldade encontrada pelos autores de entrar na justiça para defesa de seus direitos, a possibilidade do uso inadequado das obras intelectuais, o óbice à identificação do infrator e posterior impossibilidade de punição, aliados à falta de informação sobre os direitos do autor e dos usuários têm sido fatores impeditivos para a difusão de materiais abertos para uso livre. A liberdade de uso é primordial para a difusão de conhecimento e consequente "inclusão" educacional, principalmente em países em desenvolvimento.

A informação não está distribuída de forma homogênea ao redor do globo e as formas de sociabilidade, bem como os processos de inclusão e exclusão, estão cada vez mais ligados ao acesso à tecnologia e à informação. Uma doutrina de direito de autor que absolutize conceitos e lhes negue contingência [...] é um obstáculo à compreensão da dimensão política envolvida na proteção dos direitos autorais na Internet. (Valente, 2013, p. 120-121)

Tendo em vista todos esses fatores, torna-se necessário encontrar mecanismos que contemplem o direito ao livre acesso como forma de estímulo à criação de novas obras e, ao mesmo tempo, respeitem e assegurem os direitos do autor (Pinto et al., 2011). Os defensores do movimento acesso aberto, em oposição ao maximalismo 
autoral, desenvolveram modelos alternativos privados de adesão voluntária (Valente, 2013) com base em licenças de uso.

\section{LICENÇAS DE USO}

Os recursos de aprendizagem disponibilizados nos repositórios podem ser textos, software, vídeos, fotos, músicas e outros. A informação a respeito das licenças desses materiais é muito importante, pois auxilia os usuários a conhecer as permissões e as restrições quanto aos direitos autorais, facilitando o processo de escolha de determinado objeto cuja licença mais se adeque a suas necessidades (Sabino e Kon, 2009).

As licenças de uso são "documentos" nos quais os autores cedem alguns ou todos os seus direitos patrimoniais que, de outra forma, estariam protegidos pelas leis vigentes (Sabino e Kon, 2009). Os autores, mediante licenças, autorizam o "não autor" a utilizar, copiar, redistribuir, atualizar, modificar sua obra, entre outras permissões. Há, portanto, um contrato bilateral entre as duas partes, representado pelas licenças de uso, e ao usuário cabe observância dos deveres ali previstos (Marcacini, 2012).

Vale ressaltar que é proibido, no Brasil, ao autor ceder os direitos morais. Independentemente do tipo de licença de direitos patrimoniais escolhida, sempre serão assegurados os direitos morais, entre os quais o direito de reivindicar a autoria da obra. Outro ponto importante é que cabe ao autor ou à editora, quando os direitos forem cedidos a esta, acionar o judiciário quando houver ofensa aos direitos autorais.

A disponibilização para uso das obras pode variar desde "Todos os direitos reservados", ou copyright (também identificado pelo símbolo (C), até nenhum direito reservado, que equivale ao domínio público, com diversas modalidades de licenças, escolhidas pelo autor, entre esses dois extremos com restrições e liberdades diversas. A saber:

- Copyright ou “Todos os direitos reservados": não é permitido nenhum uso da obra parcial ou completa sem autorização do autor e/ou da editora, exceto o uso de passagens da obra para fins de estudo, crítica ou polêmica, e outras pouquíssimas exceções previstas no artigo 46 da LDA.

Quando não há nenhuma indicação de licença e termos de uso na obra, esta omissão deve ser entendida como "Todos os direitos reservados", pois, segundo o artigo $4^{\circ}$ da lei n. 9.610/1998, "interpretam-se restritivamente os negócios jurídicos sobre os direitos autorais", ou seja, “em matéria de direitos autorais, aquilo que não foi expressamente permitido é proibido" (Marcacini, 2012, p. 336).

A restrição total aos direitos autorais não permite que o conteúdo seja um REA, pois não permite nenhuma das quatro liberdades.

- Licenças: permitem alguns direitos de uso, porém restringem outros, de acordo com a escolha do autor, sem que seja necessária a sua autorização para os usos permitidos na licença. Quanto mais permissões forem liberadas, maior interoperabilidade terá o REA e mais oportunidades de colaboração surgirão (Educação Aberta, 2011).

Deve ser analisado caso a caso o tipo de licença para saber quais suas permissões e limitações. Por exemplo, o autor pode permitir distribuição 
e cópia de sua obra, porém proíbe o uso comercial. Nesse caso, se a obra for utilizada com fins comerciais, haverá infração aos direitos do autor, e o usuário sofrerá as sanções legais em um processo judicial.

As licenças Creative Commons podem ser citadas como meio-termo legal entre os dois extremos, em que os autores podem escolher como e quanto desejam autorizar o uso, cópia e recriação de suas obras (Lima e Santini, 2008).

Para que seja considerado REA, segundo a Recursos Educacionais Abertos (s/d.), a licença deve permitir as quatro liberdades (4R), quais sejam: reutilizar, revisar, remixar e redistribuir.

- Domínio público ou "Nenhum direito reservado": a obra pode ser utilizada livremente em seu inteiro teor, podendo ser alterada, atualizada, remixada, distribuída, copiada e até mesmo utilizada com fins comerciais, sem que seja necessária a prévia autorização. Toda obra em domínio público é um REA.

Cumpre salientar, ainda que de forma repetida, que, sempre que uma obra intelectual for utilizada, deve ser citada a sua autoria.

Há inúmeras possibilidades para redigir o texto de uma licença. ${ }^{4} \mathrm{O}$ criador pode desde escrever na própria obra os usos permitidos e proibidos até reaproveitar licenças já consolidadas na comunidade, prática mais comum atualmente, como a Creative Commons ${ }^{5}$ (CC) e a General Public Licence (GPL). ${ }^{6}$ Segundo Sabino e Kon (2009), a proliferação de licenças deve ser evitada, pois gera trabalho adicional aos usuários, uma vez que se torna necessário estudar os termos de cada nova licença presente nos objetos de aprendizagem que irão utilizar.

Creative Commons é uma organização não governamental e sem fins lucrativos, responsável pela criação de vários tipos de licenças que permitem a cópia e o compartilhamento da obra com menos restrição, dando ao autor o poder de definir quais os usos que terceiros podem dela fazer (Educação Aberta, 2011). Está disponível em mais de cinquenta países, é de fácil utilização, didática, flexível e menos burocrática que as legislações que não acompanham a evolução tecnológica

4 A título de exemplo de vários tipos de licença em um mesmo referatório, ver o documento Política de acesso aberto e de direitos autorais do RCIpea: Licença Padrão do RCIpea, criado pelo Instituto de Pesquisa Econômica Aplicada (IPEA). Disponível em: <http:// repositorio.ipea.gov.br/static/docs/POLITICA_DE_DIREITOS_AUTORAIS _LICENCA_PADRAO_DO_RCIpea.pdf>.Acesso em: 13 out. 2017.

5 Disponível em: <http://creativecommons.org >. Para uma visão geral do conceito, tipos de licenças possíveis, permissões, limitações, vantagens e aplicações das licenças CC, ver o folheto criado pelo Repositório Institucional da Universidade de Brasília (UnB), disponível em: <http://www.bce.unb.br/wp-content/uploads/2014/08/folheto-creative-commons.pdf $>$. Acesso em:

6 Disponível em: <www.gnu.org/licenses/gpl.html>. Para uma explicação das principais licenças de software livre e visualização do quadro comparativo entre elas, ver o manual de procedimento para validação de obras intelectuais, criado pelo Banco Internacional de Objetos Educacionais (BIOE), disponível em: <http://objetoseducacionais2.mec. gov.br/retrievefile/procedimentos>. Acesso em: 10 out. 2017. 
(Pinto et al.,2011). Tem sido adotada como padrão mundial (Amiel e Santos, 2013; Pinto et al., 2011), e em 2004 o governo brasileiro anunciou oficialmente seu apoio à iniciativa (Lima e Santini, 2008).

Os tipos de licenças CC estão fundamentados em quatro condições que podem ser combinadas, são elas: atribuição (BY); uso não comercial (NC); não a obras derivadas (ND); e compartilhamento pela mesma licença (SA). A "atribuição" deve estar presente em todas as licenças no Brasil, por tratar-se de direito moral de se atribuir à obra sua autoria, sendo a menos restritiva quanto ao uso ou modificação. A condição de "uso não comercial" impede o uso comercial da obra. A "não a obras derivadas" não permite a modificação ou "remix" da obra, e a de "compartilhamento pela mesma licença" permite o uso e a modificação, desde que a obra derivada seja distribuída com a mesma licença que a original. Utilizando as quatro condições, é possível criar seis tipos de licença: BY; BY-SA; BY-ND; BY-NC; BY-NC-SA; e BY-NC-ND, sendo a primeira a menos restritiva até a última, mais restritiva.

A escolha da licença deve ser feita de acordo com as regras e termos de uso do repositório em que o autor pretende disponibilizar sua obra. Há repositórios que utilizam o sistema do Creative Commons, há outros que têm métodos próprios personalizados para a seleção da licença (por exemplo, o repositório do IPEA), e há ainda os que usam uma única licença para todos os materiais hospedados em seu sítio. É essencial vincular ao recurso educacional a licença que regulamenta seu uso, para que o usuário o utilize de forma adequada (Educação Aberta, 2011).

Todas as licenças possuem potencialidades e limitações. Morato (2013) e Parilli (2012) alertam para as limitações das licenças CC, tais como: não haver informação com destaque suficiente quanto à isenção de responsabilidade dessa organização em caso de desrespeito ao direito autoral, cabendo ao autor acionar o infrator judicialmente; e impossibilidade de arrependimento do autor, caso queira retirar a obra de circulação. Em contrapartida, Lima e Santini (2008, p. 126) entendem que essas licenças constituem um poderoso agente de mudança social e econômica, principalmente em virtude da inadequação do modelo restritivo de direitos autorais na sociedade da informação, e advertem que

o modelo de mediação da indústria cultural, que contrata e remunera os produtores de conteúdo e controla o acesso aos seus produtos, tem pouco mais de cem anos e é uma produção histórica. As novas tecnologias digitais trazem extrema facilidade para a produção e disseminação de conteúdos, além do acesso à informação e aos bens imateriais. A cultura na sociedade da informação é uma cultura pós-industrial.

A fim de facilitar a busca e o arquivamento de conteúdo aberto, foram criados os repositórios, bibliotecas digitais e revistas. Repositórios são bancos de dados nos quais são depositados e indexados os recursos, que são mantidos por instituições de ensino e pesquisa ou por outro tipo de organização com conteúdo relevante para o ensino (Associação Brasileira de Educação a Distância, 2010). Eles diferem das bibliotecas, pois a filosofia que norteia o funcionamento daqueles é baseada 
no processo de colaboração e no autoarquivamento, ${ }^{7}$ uma vez que todos podem colocar seus objetos e partilhá-los (Silva, Café e Catapan, 2010), sem a necessidade de análise prévia da instituição. Os repositórios, por sua vez, são registrados em diretórios e indexadores mundiais (também chamados de referatórios), que são sítios que não fazem o armazenamento dos recursos propriamente ditos, mas indicam os metadados que mostram quais são os repositórios que detêm recursos sobre determinado assunto (Marra, 2014).

Embora haja uma distinção entre os termos, para efeito deste estudo não houve diferenciação entre repositórios, bibliotecas, revistas ou qualquer outro sítio que disponibilize material de ensino. Utilizou-se, portanto, o termo repositório em sentido genérico.

\section{OBJETIVO}

Ante o exposto, o objetivo deste estudo é analisar as informações sobre licenças de uso e direitos autorais fornecidas aos usuários nos repositórios brasileiros.

Esta pesquisa é importante em decorrência do aumento do número de repositórios (Amiel e Santos, 2013) nos últimos anos e por haver poucos artigos sobre esse tema. A principal vantagem dos REA é que qualquer material disponível na rede pode ser utilizado e adaptado, o que torna a educação mais acessível. Os REA também estimulam a cultura participativa, desenvolvimento e cooperação de materiais, acompanhando a evolução da sociedade do conhecimento.

\section{MATERIAIS E MÉTODOS}

Trata-se de uma pesquisa de análise de conteúdo quantitativa e qualitativa (Bardin, 1970 apud Caregnato e Mutti, 2006), descritiva (Silveira e Córdova, 2009), com levantamento de dados realizado eletronicamente. Este estudo possui natureza aplicada, pois objetiva gerar conhecimentos para aplicação prática.

As informações coletadas foram extraídas de endereços eletrônicos disponibilizados em dois referatórios internacionais: Directory of Open Access Repositories (OpenDOAR) ${ }^{8}$ e Registry of Open Access Repositories (ROAR); ${ }^{9}$ e um nacional: Mapa de Iniciativas de Recursos Abertos (MIRA), ${ }^{10}$ no período de 20 de dezembro de 2014 a 10 de janeiro de 2015.

Seis passos foram adotados nesta pesquisa:

\section{Refinamento por país}

Nesta etapa foram acessados os referidos referatórios para encontrar os repositórios brasileiros. Para isso foi adotada a seguinte metodologia:

7 O autoarquivamento é o mecanismo de depósito realizado pelo próprio autor em repositórios institucionais, recomendado pelo movimento de acesso aberto à informação científica (Assis, 2013).

8 Disponível em: <http://www.opendoar.org/about.html>. Acesso em: 16 fev. 2015.

9 Disponível em:< http://roar.eprints.org/information.html>. Acesso em: 16 fev. 2015.

10 Disponível em: <http://mira.org.br/sobre-o-projeto/>. Acesso em: 16 fev. 2015. 


\subsection{OpenDOAR:}

- Na página inicial foi selecionado o link para a pesquisa dos repositórios (Search for repositories);

- Na página seguinte, no campo Any Country, foi selecionado o país Brazil. Os demais campos permaneceram inalterados.

1.2. ROAR e MIRA: Na página inicial, em ambos os diretórios no campo Any Country/Países, foi selecionado o país Brazil. Os demais campos permaneceram inalterados.

\section{Análise dos repositórios}

Todos os repositórios listados nos referatórios, após refinamento por país, foram analisados, sendo descartados os dúplices e os inativos. Os repositórios com endereços eletrônicos desatualizados, fato já constatado por Marra (2014), foram atualizados por meio do mecanismo de busca do Google.

Os dados coletados foram organizados em uma planilha.

\section{Análise do tipo de licença de uso dos repositórios}

Entre os repositórios já selecionados na planilha, foi analisado qual o tipo de licença de uso do site. Nessa etapa foi aberto o site na internet e feita uma análise visual para conferir se havia licença exposta em sua página inicial e, em caso positivo, transcrita na planilha. Não foi considerada a licença quando exposta em local diverso da página inicial.

4. Análise do local em que estavam disponibilizadas as informações a respeito dos direitos autorais

Nessa fase foi analisado se havia ou não informação disponível aos usuários a respeito dos direitos autorais, mediante o seguinte processo:

- Na página inicial foram acessados todos os links disponíveis, um a um, independentemente do assunto que tratavam, a fim de localizar o(s) $\operatorname{link}(s)$ em que havia informações sobre direitos autorais;

- Na página seguinte que se abria, após acessar o link, foram analisadas as informações disponibilizadas;

- Caso não houvesse nenhuma informação sobre direitos autorais em nenhum link do referatório, era anotado na planilha;

- Caso houvesse informação sobre direitos autorais, seguia-se para o próximo passo.

5. Análise das informações a respeito dos direitos autorais

Quando havia informações a respeito de direitos autorais, era preenchida uma segunda planilha, anotando-se as informações disponibilizadas de acordo com cinco critérios:

- definição de direitos autorais;

- definição e/ou citação de direitos morais;

- definição e/ou citação de direitos patrimoniais;

- tipo de licença de uso;

- usos permitidos;

- usos proibidos; e

- citação do número da lei de direitos autorais (lei n. 9.610/1998). 


\section{Análise dos dados e elaboração das tabelas}

Por fim, quando todos os dados referentes ao tipo de licença de uso e todos os referentes às informações sobre os direitos autorais estavam discriminados nas planilhas, foram elaboradas as Tabelas 1 e 2 .

\section{RESULTADOS}

Com vistas a facilitar a compreensão dos dados coletados, os resultados serão exibidos de acordo com os passos adotados na metodologia deste estudo.

Para a coleta de dados, não foram considerados os metadados, já que grande parte da população não os conhece, e por entender que as informações sobre os

Tabela 1 - Quantidade de sítios em que havia o tipo de licença na página inicial de acordo com o tipo de licença

\begin{tabular}{|c|c|c|}
\hline Quantidade & & Tipo de licença na página inicial \\
\hline 55 & & Não havia \\
\hline 40 & & Copyright ou "Todos os direitos reservados" \\
\hline 20 & Creative Commons & \begin{tabular}{|l}
$8-$ CC BY \\
5 - CC BY NC ND \\
$4-$ CC BY NC \\
2 - CC BY NC SA \\
$1-$ CC BY SA \\
\end{tabular} \\
\hline 1 & \multicolumn{2}{|c|}{ Todos os direitos e conteúdos deste Portal são de uso compartilhado. } \\
\hline 1 & \multicolumn{2}{|c|}{$\begin{array}{l}\text { O autor é titular dos direitos autorais dos documentos disponíveis neste repositório e é } \\
\text { vedada, nos termos da lei, a comercialização de qualquer espécie sem sua autorização prévia. }\end{array}$} \\
\hline 1 & \multicolumn{2}{|c|}{$\begin{array}{l}\text { Os documentos disponíveis no RI da USCS são de responsabilidade de seus autores, } \\
\text { conforme a legislação que rege o direito autoral no país (Lei n. 9.610/98). }\end{array}$} \\
\hline
\end{tabular}

Fonte: Banco de dados da pesquisa.

Elaboração da autora.

Tabela 2 - Divisão das informações disponíveis nos sítios de acordo com critérios a respeito dos direitos autorais

\begin{tabular}{l|c}
\hline Quantidade & Informações sobre direitos autorais \\
\hline 6 & Definição direitos autorais \\
\hline 7 & Definição direitos patrimoniais \\
\hline 7 & Definição direitos morais \\
\hline 23 & Tipo de licença dos REA \\
\hline 25 & Usos permitidos \\
\hline 12 & Usos restritos \\
\hline 11 & Menção à lei de direitos autorais n. 9.610/1998 \\
\hline
\end{tabular}

Fonte: Banco de dados da pesquisa.

Elaboração da autora. 
direitos autorais, por estarem intrinsecamente ligadas aos REA, devem estar visíveis a todos os usuários, independentemente de sua cultura digital. Assim sendo, segue a análise dos resultados:

1. Na fase de refinamento por país foi observado um total de 242 repositórios no Brasil, divididos por referatório:

- OpenDoar $=84$

- $\quad \mathrm{ROAR}=147$

- $\quad$ MIRA = 11

2. Foram descartados 100 repositórios que estavam em duplicidade, e 24 repositórios que estavam inativos, restando para estudo 118 sítios. Destes, foram atualizados 14 endereços eletrônicos por meio do mecanismo de busca do Google.

3. Observou-se que em 55 sítios não possuíam nenhuma licença de uso, 40 sítios eram copyright ou "Todos os direitos reservados", e 20 utilizavam a licença Creative Commons, conforme Tabela $1 .{ }^{11}$

4 e 5. Foi elaborada uma segunda planilha com todos os repositórios que disponibilizaram informações a respeito dos direitos autorais divididos em cinco critérios já referidos no item metodologia. Dos 118 sítios analisados, somente em 39 ( $\mathrm{n}=33,05 \%)$ havia algum tipo de informação sobre direitos autorais, disponibilizados em diversos locais, conforme pode ser observado na Tabela $2 .{ }^{12}$

\section{DISCUSSÃO}

O movimento aberto tem crescido em todo o mundo, inclusive no Brasil, que, em 2010, aparecia na quinta colocação entre os vinte países com maior número de repositórios registrados no ROAR ( $n=71$ ), segundo Müller (2012). Já em 2015 aparece na quarta colocação, ao lado do Japão, com 135 repositórios registrados. ${ }^{13}$ Esse movimento se consolidou no país por meio das iniciativas de instituições brasileiras na criação de repositórios institucionais, temáticos, bibliotecas digitais e de publicações eletrônicas.

De acordo com Müller (2012), o mundo caminha, de forma irreversível, em direção a um modelo de educação não formal, adaptável e flexível, com compartilhamento de documentos, atendendo aos interesses de quem deseja aprender. Nascimento (2008, p. 352) ensina que

a disponibilização de recursos em ambientes abertos possibilitará muito mais do que o simples compartilhamento de materiais, pois a pressão causada pelo

11 A planilha elaborada com todos os sítios analisados está exposta na página <https:// drive.google.com/file/d/0BzkyizB9sbK7WFdqOVFrM1BiVHM/view?usp=sharing> .

12 A planilha completa elaborada nesta etapa encontra-se no endereço <https://docs.google.com/document/d/1Z4cFWFhbli399h4HX42y6Nmg0HEsaGqGLog-1U1E21w/ edit?usp=sharing $>$.

13 Disponível em: <http://roar.eprints.org/view/geoname/>. Acesso em: 16 fev. 2015. 
acesso, contribuição e participação de um número maior de indivíduos tenderá a afetar a demanda por mais eficiência, melhores métodos de ensino e melhor aprendizagem através do desenvolvimento de pensamento crítico e criativo, com consequente mudança no processo de ensino-aprendizagem e no paradigma educacional. Possibilitará também que sociedades menos desenvolvidas tenham acesso mais rápido a informações produzidas por profissionais de instituições renomadas em países desenvolvidos.

Os recursos educacionais abertos estão em sintonia com o novo paradigma de educação, pois asseguram aos usuários acesso, adaptação e cópia de conteúdos educacionais sem ressalvas ou penalizações desde que respeitadas as restrições e citações devidas, pois, mesmo quando os recursos são abertos, os direitos autorais devem ser preservados, seguindo os limites determinados pelo autor no repositório (Pinto et al., 2011). Apesar de ser uma tendência mundial o compartilhamento, observa-se ainda resistência de algumas instituições e professores, porque temem sofrer as consequências pelo uso inapropriado de seus recursos e pela competição antiética, além da dificuldade de entrar na justiça quanto a questões de propriedade intelectual (Marcacini, 2012).

Os direitos autorais têm sido alvo de ampla mobilização por parte da comunidade internacional, preocupada com a proteção da integridade e com a garantia dos direitos de exploração econômica das obras científicas para seus titulares (Abrão, 2002 apud Araya e Vidotti, 2009). Isso levou à edição de normas de aplicação internacional para disciplinar a defesa do direito de autor, tais como a Convenção de Berna, a Convenção Universal de Genebra e a Convenção de Roma, das quais o Brasil é signatário.

No Brasil, essa matéria é disciplinada pela LDA, editada em 1998, que não foi idealizada para o contexto das tecnologias da informação, mas para uma realidade social distinta que, apesar das alterações posteriores, ainda está muito distante da realidade atual. Contudo, deve-se ressaltar que, mesmo "desatualizada”, essa norma é válida e rege os direitos autorais e, consequentemente, seus fundamentos devem ser informados aos usuários dos repositórios para que não incorram em ilegalidade e desrespeitem os direitos dos autores. No entanto, foi observado, neste estudo, significante falta de informação ou deficiência desta no que se refere aos direitos autorais e licenças de uso. Os resultados obtidos serão discutidos de acordo com os temas analisados: licenças de uso dos repositórios e informações sobre direitos autorais.

\section{LICENÇAS DE USO DOS REPOSITÓRIOS}

Nesta pesquisa, constatou-se que praticamente metade dos sítios não possuía o tipo de licença de uso na página inicial $(n=55)$, conforme Tabela 1 . De acordo com Marcacini (2012, p. 335), "com a expansão da Internet, o desconhecimento das leis pela população em geral levou à interpretação de que aquilo que estivesse [...] aberto e disponível poderia ser livremente utilizado", porém qualquer utilização da obra quando não há licença depende da autorização do autor, pois, em matéria de direitos autorais, o que não é expressamente permitido é proibido. 
Ou seja, quando não há nenhum tipo de licença ou termo de uso, deve-se entender como "Todos os direitos reservados".

Observou-se também que quarenta sítios possuíam em sua página inicial a inscrição copyright ou "Todos os direitos reservados", não sendo possível que nenhum indivíduo faça uso do site, exceto nos casos de permissão. Portanto, no total, 95 ( $n=80,50 \%)$ endereços eletrônicos não permitem quaisquer das quatro liberdades características dos REA. Esse fato denota completa desconexão entre o movimento acesso aberto e os propósitos dos repositórios. O termo REA, conforme estudado na introdução, denota material de ensino/aprendizagem em domínio público ou sob licença aberta ou com poucas restrições. $O$ fato de logo na página inicial não haver nenhuma informação a respeito da licença de uso ou ser "Todos os direitos reservados" no mínimo demonstra falta de conhecimento dos princípios do movimento acesso aberto por parte dos organizadores dos repositórios e da necessidade de haver uma licença para proteção tanto do usuário quanto do autor.

Amiel e Santos, em estudo realizado em 2013, investigaram os termos de uso de doze portais contendo recursos digitais educacionais no Brasil, em três camadas: pela página principal, pela página de metadados e por uma análise aleatória de recursos. Dos doze portais investigados, dois não incluíam informação alguma sobre os direitos de uso em sua página inicial. Três sites utilizaram a terminologia de copyright ou "Todos os direitos reservados" sem maiores esclarecimentos. Ou seja, quase metade dos portais analisados não apresentava termos de uso de acordo com o movimento aberto.

No entanto, o fato de um repositório possuir uma licença restritiva na página inicial não significa que os recursos que ele contém também a possua. Rossini (2010) e Amiel e Santos (2013) observaram que há ambiguidade entre os termos de uso constantes na página inicial do repositório e o recurso educacional em si e recomendam que os portais explicitem na página principal, claramente, a natureza do serviço prestado. Ensinam também que aos recursos em si devem ser atrelados os termos de uso deste, pois a falta de informação atrelada ao recurso não permite que o usuário identifique o que pode ou não fazer com o recurso encontrado. Recomendam ainda que os repositórios consolidem seus termos em uma linguagem clara e simplificada, utilizando licenças já estabelecidas, como a CC.

Segundo Araya e Viscontti (2009), no Brasil a licença CC é ainda pouco conhecida e utilizada, o que pode ser confirmado com o resultado deste estudo, pois somente em vinte casos $(n=16,95 \%)$ ela foi adotada na página inicial dos repositórios analisados (Tabela 1). Constatou-se também que o conteúdo explicativo dos termos de uso da licença é insuficiente, mostrando somente de forma sucinta os direitos e deveres do usuário, e que nem sempre corresponde à licença apresentada na página inicial do site. Como exemplo dessa falha na informação, pode-se utilizar o site Escola Digital, ${ }^{14}$ que apresenta na página inicial, na parte inferior, a licença CC BY, ou seja, "atribuição", porém, ao se clicar no símbolo dessa licença, o usuário é remetido a uma página do Creative Commons, em inglês, que explica a licença CC BY NC ND, ou seja, "atribuição", "não comercial" e "não derivada".

14 Disponível em: <http://escoladigital.org.br/>. Acesso em: 10 out. 2017. 
Neste estudo, das vinte licenças CC, cinco possuem restrição ND, a qual impede que a obra original sofra qualquer tipo de modificação ou que seja "remixada" para a criação de uma obra nova, podendo ser executada e distribuída somente cópia exata da obra original (Pinto et al., 2011). Esse tipo de restrição impede duas das quatro liberdades do REA: revisar e remixar. Para o referido autor, a inclusão de requerimentos e restrições em licenças abertas torna o conteúdo menos aberto do que seria sem estes, porém não há um consenso na comunidade de quais restrições não devem nunca estar incluídas nas licenças abertas, ou devem estar às vezes ou sempre, para ser considerado REA.

O "remix" é um dos grandes benefícios do movimento aberto, pois permite que outros façam modificações nos recursos já criados. Parte-se do princípio de que conhecimento novo é criado com base na informação que está acessível e que é adaptada. "Remixar" inclui: inserir, remover ou misturar componentes, mudar a sequência das atividades, editar ou alterar imagens, texto, áudio, vídeo etc. Araya e Vidotti (2009) entendem que a colaboração e a remixagem, favorecidas pelos novos serviços e aplicações propiciados pela evolução da web, são práticas presentes que contribuem para o exponencial crescimento de produtores de informação. Uma parcela importante da humanidade deixa de ser mero consumidor de bens simbólicos e passa a integrar-se em uma sociedade que vê na colaboração e no remix uma nova forma de criação, uso e disseminação de conteúdo intelectual.

Os repositórios que apresentaram de forma mais completa e clara os termos de uso da licença CC foram o Repositório Digital da Universidade Municipal de São Caetano do Sul ${ }^{15}$ e o Repositório Institucional da UnB. ${ }^{16}$

As demais licenças, se é que podem ser consideradas licenças, encontradas neste estudo foram: "Todos os direitos e conteúdos deste Portal são de uso compartilhado"; ${ }^{17}$ "O autor é titular dos direitos autorais dos documentos disponíveis neste repositório e é vedada, nos termos da lei, a comercialização de qualquer espécie sem sua autorização prévia"; 18 e "Os documentos disponíveis no RI da USCS são de responsabilidade de seus autores, conforme a legislação que rege o direito autoral no país (lei n. 9.610/98)" ${ }^{19}$ A primeira licença é confusa, pois não há definição do que seja o uso compartilhado. No Novo dicionário Aurélio da lingua portuguesa (Ferreira, 2014), o verbo compartilhar significa: ter ou tomar parte em; partilhar; compartir; usar em comum, o que não demonstra quais os usos permitidos e proibidos dos recursos disponíveis no repositório. Já a segunda veda o uso comercial, porém não explicita quais são as demais vedações, se é que há, e permissões, os direitos autorais

15 Ver o manual do usuário. Disponível em: <http://repositorio.uscs.edu.br/Manual_RI-USCS.pdf>. Acesso em: 3 mar. 2015.

16 Disponível em: http: <//www.bce.unb.br/wp-content/uploads/2014/08/folheto-creative-commons.pdf>. Acesso em: 23 fev. 2015.

17 Site da Secretaria da Educação do Estado da Bahia. Disponível em: <http://ambiente. educacao.ba.gov.br/>. Acesso em: 16 fev. 2015.

18 Site do Repositório Digital da UFRGS - LUME. Disponível em: http://www.lume. ufrgs.br/. Acesso em: 16 fev. 2015.

19 Disponível em: <http://repositorio.uscs.edu.br/>. Acesso em: 23 fev. 2015. 
protegidos, e quais os tipos de licenças utilizadas. Por fim, a terceira apenas cita a LDA sem disponibilizar maiores esclarecimentos.

Amiel e Santos (2013, p. 129) ensinam que "na lógica do movimento REA, a clareza quanto aos termos de uso dos recursos é uma condição básica para que recursos sejam aproveitados em sua totalidade por usuários finais com respeito aos autores e detentores dos direitos". E aponta a necessidade dos portais consolidarem seus termos em uma linguagem única ou explicitarem claramente as ambiguidades inerentes ao modelo adotado.

O sítio do Repositório Institucional da Fiocruz - ARCA - pode ser citado como exemplo de uso de termos claros de uso dos recursos expressos na página inicial:

Este repositório institucional é regido pela Política Institucional de Acesso Aberto à Produção Científica e Intelectual da Fundação Oswaldo Cruz, que visa garantir à sociedade o acesso gratuito, público e aberto ao conteúdo integral de toda obra intelectual produzida pela Fiocruz. O conteúdo deste sítio pode ser utilizado para todos os fins não comerciais, respeitados e reservados os direitos morais dos autores. Equivalente a CC BY NC (Atribuição-Não Comercial).

Sendo que há links em "Política Institucional de Acesso [...] Oswaldo Cruz", que remete o usuário à Portaria de Política de Acesso Aberto da Instituição onde há informações a respeito dos direitos autorais.

Sugere-se que, ao final da página inicial do repositório, contenha a seguinte descrição:

Este repositório institucional é regido pelos Termos de Uso e pela Lei de Direitos Autorais, e visa garantir à sociedade o acesso gratuito e aberto às obras intelectuais neste site disponibilizadas. Todo o conteúdo deste site, exceto no material que está identificado de outra forma, está licenciado sob uma licença (descrever o tipo de licença mais frequente do repositório, ou colocar a imagem da licença $\mathrm{CC}$, se for o caso). Toda violação destes direitos estará sujeita às penalidades prescritas em lei.

Caso possível, deve haver um link em "Termos de Uso" que remeta a uma página com todas as informações a respeito dos direitos autorais e termos de uso. Um link em "Lei de Direitos Autorais" que dê acesso a uma página com a referida lei e, por fim, um link em "licença", que remeta à explicação de todas as licenças possíveis de serem utilizadas nos recursos com suas permissões e restrições. Caso a licença seja CC, recomenda-se que seja utilizada a informação em português nos moldes da efetuada pelo Repositório Institucional da UnB, já indicado anteriormente.

\section{INFORMAÇÕES SOBRE DIREITOS AUTORAIS}

Somente em 39 repositórios ( $\mathrm{n}=33,05 \%)$ há informações sobre direitos autorais segundo os critérios adotados na metodologia. E apenas em dois casos as informações sobre esses direitos foram suficientes, de acordo com os parâmetros desta pesquisa. Não foram encontrados estudos que tratem dessa matéria para que fossem comparados e discutidos os resultados desta pesquisa. 
Os oito repositórios elencados a seguir foram os que disponibilizaram mais informações para o usuário de acordo com os critérios desta pesquisa, e cujos dados podem ser utilizados para ser compartilhados e/ou "remixados":

1. Repositório Institucional da Fiocruz - ARCA: apresenta todas as informações a respeito dos direitos autorais utilizadas como parâmetro nesta pesquisa, porém essas informações não estão concentradas em um só local, mas em três links a partir da página inicial, o que dificulta o acesso rápido à informação. Apresenta algumas informações na Portaria de Política de Acesso que utiliza uma linguagem mais "rebuscada", podendo ser difícil de entender para alguns indivíduos. Outra dificuldade encontrada foi pelo fato de as informações a respeito das licenças dos recursos estarem disponibilizadas em inglês.

2. Repositório do Conhecimento do IPEA: apresenta as informações ao clicar no ícone "Direitos autorais" da página inicial. ${ }^{20}$ As informações foram divididas em seis documentos: visão geral; licença padrão do RCIpea, licença padrão das publicações; processo de notificação em caso de violação de direitos autorais; e avisos de responsabilidade. Observou-se que as informações são claras e objetivas, embora divididas em mais de um documento.

3. Escola Nacional de Saúde Pública Sérgio Arouca: apresenta um manual de Direitos Autorais, Acesso Aberto e Repositório Institucional ${ }^{21}$ em linguagem objetiva e clara, no entanto não aponta os tipos de licenças utilizadas nos recursos.

4. Dia a Dia: possui três vídeos didáticos, com cerca de quinze minutos cada, com explicações a respeito dos direitos autorais apresentados por Sérgio Said Staut Júnior. Há também informações a respeito dos direitos autorais em Perguntas Frequentes. ${ }^{22}$

5. Repositório Institucional - UnB: apresenta uma explicação completa e em português a respeito das Licenças $\mathrm{CC}$, já comentado anteriormente.

6. Acervo de Recursos Educacionais em Saúde - UNAUS: no documento Termos de $\mathrm{Uso}^{23}$ apresenta informações relevantes, com linguagem clara e sucinta quanto ao direito autoral, no entanto não o define, tampouco cita a LDA.

7. BIOE: no manual de procedimento para validação de obras intelectuais, ${ }^{24}$ demonstra a forma para validação das obras, formas de cessão da obra,

20 Disponível em: <http://repositorio.ipea.gov.br/rights/index.jsp>. Acesso em: 23 fev. 2015.

21 Disponível em: <http://www6.ensp.fiocruz.br/repositorio/sites/default/files/arquivos/ Manual\%20de\%20Direitos\%20Autorais\%20ENSP_0.pdf>. Acesso em: 23 fev. 2015.

22 Disponível em: http://www.gestaoescolar.diaadia.pr.gov.br/modules/conteudo/conteudo.php? conteudo=72. Acesso em: 23 fev. 2015.

23 Disponível em: https://ares.unasus.gov.br/acervo/static/files/Termos\%20de\%20Uso_ ARES.pdf. Acesso em: 25 fev. 2015.

24 Disponível em: http://objetoseducacionais2.mec.gov.br/retrievefile/procedimentos. Acesso em: 25 fev. 2015. 
tipos de licença, porém não define direito autoral, nem o que são e quais são os direitos morais e patrimoniais.

8. Biblioteca Digital Teses e Dissertações USP: O guia prático I: introdução à propriedade intelectual (Souza e Murakawa, 2014) possui 32 páginas, porém há índice, o que facilita a busca para a informação desejada. Não delimita quais os tipos de licença utilizadas no site e quais os usos permitidos e proibidos.

Embora esses repositórios tenham disponibilizado as informações, observouse que, em alguns casos, foram apresentados manuais de direitos autorais longos e com linguagem complexa, o que também pode ser um fator impeditivo do acesso à informação.

Sugere-se que as informações disponibilizadas sobre os direitos autorais sejam concentradas no link "Direitos Autorais", na página inicial, e que sejam completas, abarcando os seguintes itens:

- definição de direitos autorais;

- definição e citação dos direitos morais;

- definição e citação dos direitos patrimoniais;

- tipo de licença utilizada nos recursos;

- usos permitidos;

- usos proibidos;

- citação da legislação aplicável.

As informações devem ser prestadas de forma clara, objetiva e sucinta, nesse primeiro momento, com links para documentos com informações mais aprofundadas em forma de manuais, vídeos ou outras, para que o usuário acesse, caso tenha interesse.

Pode-se observar que há atualmente no Brasil duas limitações ao uso dos REA: primeira é a inadequação da legislação que trata dos direitos autorais, que não evoluiu na mesma velocidade que a sociedade da informação; e a segunda é a falta de informação nos repositórios que disponibilizam material "aberto" a respeito desses direitos. A primeira limitação tem sido contornada com o uso de licenças privadas, pois a evolução legislativa é lenta e não se pode aguardar uma nova lei para que o conhecimento seja disseminado. No entanto, a falta de informação é um problema grave que independe de leis, mas depende de que as instituições de ensino implementem programas de educação continuada a discentes e docentes para conscientização sobre os direitos dos autores e sobre o movimento acesso aberto.

Para Rossini (2010), o Brasil está ainda em processo de abertura de conteúdo e carece de um conjunto coerente de objetivos funcionais e políticas de informação sobre os direitos autorais e as regras relacionadas à filosofia REA. É necessária uma política pública que determine um conjunto de recomendações e protocolos, pelo Ministério da Educação (MEC) e Governo Federal, para padronização da informação.

Enquanto não há uma política pública, cabe aos repositórios disponibilizar informações adequadas, suficientes e verídicas a respeito dos direitos autorais, licenças do site e dos recursos franqueados, em local de fácil visualização e acesso, 
tornando possível ao usuário escolher qual recurso mais se adapta a suas necessidades e manter uma relação de cooperação com o autor, em que direitos e deveres de ambos são observados.

Esta pesquisa não visa criticar a falta de informações sobre os direitos autorais dos sites analisados, nem determinar quais devem ser as licenças e os termos de uso. Visa demonstrar o lapso nas informações sobre esse tema em um período de crescente abertura digital e apontar, com base em exemplos concretos, as informações mais completas para serem utilizadas e "remixadas" (por que não?) nos repositórios educacionais.

Recomendamos o desenvolvimento de novos estudos para que a questão levantada seja debatida e divulgada. A adoção de uma política nacional de informação sobre os direitos autorais nos repositórios (no sentido abrangente do termo, que inclui repositórios, bibliotecas digitais, revistas etc.) garantirá o conhecimento dos atores envolvidos no movimento acesso aberto e, consequentemente, assegurará o respeito aos direitos autorais e oferecerá maior visibilidade à produção de conhecimento.

\section{CONCLUSÃO}

O principal objetivo desta pesquisa foi analisar as informações fornecidas aos usuários nos repositórios educacionais brasileiros no que tange aos direitos autorais e licenças de uso. Foram analisados 118 endereços eletrônicos. Constatou-se que em $80,50 \%$ dos sítios, na página inicial, não há nenhuma referência ao tipo de licença ou são copyright ou "Todos os direitos reservados", o que denota completa desconexão entre o movimento acesso aberto e os propósitos do repositório. A licença Creative Commons é utilizada em $16,94 \%$ dos sítios. Somente em 33,05\% dos sítios ( $\mathrm{n}=39)$ havia algum tipo de informação sobre direitos autorais.

Concluiu-se que não foram disponibilizadas informações mínimas aos internautas, tanto quanto ao tipo de licença nos sites, quanto em relação aos direitos autorais, na maioria dos repositórios analisados. $\mathrm{O}$ acesso à informação permite a realização de escolhas mais qualificadas pelo usuário para o exercício de seus direitos. A falha na informação da matéria em questão pode gerar a ofensa aos direitos do autor, pois ainda predomina a ideia de que todo o material disponível na internet é de uso livre.

Para que a filosofia do movimento REA seja atingida em sua completude, deve haver informação adequada, suficiente e veraz quanto às licenças de uso dos recursos e direitos autorais. Dessa forma, os recursos serão aproveitados em sua totalidade por usuários finais com respeito aos autores e seus direitos.

\section{REFERÊNCIAS}

ABED - Associação Brasileira de Educação a Distância. Referatórios de objetos de aprendizagem e outros recursos educacionais. [Extraído de Fredric M. Litto, Aprendizagem a distância. São Paulo: Imprensa Oficial, 2010]. Disponível em: <http:// www.abed.org.br/site/pt/midiateca/referatorio/>. Acesso em: 26 ago. 2014. 
Abrão, E. Y. Direitos de autor e direitos conexos. São Paulo: Editora do Brasil, 2002.

Amiel, T.; Santos, K. Uma análise dos termos de uso de repositórios de recursos educacionais digitais no Brasil. Trilha Digital, São Paulo: Universidade Presbiteriana Mackenzie, v. 1, n. 1, p. 118-133, 2013. Disponível em: <http://editorarevistas. mackenzie.br/index.php/TDig/article/view/5892>. Acesso em: 27 ago. 2014.

Araya, E. R. M.; Vidotti, S. A. B. G. Direito autoral e tecnologias de informação e comunicação no contexto da produção, uso e disseminação de informação: um olhar para as licenças Creative Commons. Informação \& Sociedade, João Pessoa: UFPB, v. 19, n. 3, p. 39-51, set./dez. 2009.

Assis, T. B. Análise das políticas de autoarquivamento nos repositórios institucionais brasileiros e portugueses. In CID: Revista de Ciência da Informação e Documentação, São Paulo: USP, v. 9, n. 2, p. 212-227, 2013.

Bardin, L. Análise de conteúdo. Lisboa: Edições 70, 1977.

Brasil. Decreto-lei n. 2.848, de 7 de dezembro de 1940. Código Penal. Disponível em: $<$ http://www.planalto.gov.br/ccivil_03/decreto-lei/Del2848compilado.htm>. Acesso em: 27 fev. 2015.

. Constituição da República Federativa do Brasil. Diário Ofcial da União, Brasília, DF, 5 out. 1988. Disponível em: <http://www.planalto.gov.br/ccivil_03/constituicao/ constituicao.htm>. Acesso em: 27 fev. 2015.

Lei n. 9.610, de 19 de fevereiro de 1998. Altera, atualiza e consolida a legislação sobre direitos autorais e dá outras providências. Diário Oficial da União, Brasília, DF, 20 fev. 1998. Disponível em: <http://www.planalto.gov.br/ccivil_03/leis/19610.htm>. Acesso em: 4 set. 2014.

. Lei n. 12.853, de 14 de agosto de 2013. Altera os arts. $5^{\circ}, 68,97,98,99$ e 100, acrescenta arts. 98-A, 98-B, 98-C, 99-A, 99-B, 100-A, 100-B e 109-A e revoga o art. 94 da lei n. 9.610, de 19 de fevereiro de 1998, para dispor sobre a gestão coletiva de direitos autorais, e dá outras providências. Diário Oficial da União, Brasília, DF, 14 ago. 2013. Disponível em: <http://www.planalto.gov.br/ccivil_03/_Ato2011-2014/2013/ Lei/L12853.htm>. Acesso em: 4 set. 2014.

.Lei n. 12.965, de 23 de abril de 2014. Estabelece princípios, garantias, direitos e deveres para o uso da internet no Brasil. Diário Ofcial da União, Brasília, DF, 24 abr. 2014. Disponível em: <http://www.planalto.gov.br/ccivil_03/_ato2011-2014/2014/lei/ 112965.htm>. Acesso em: 23 fev. 2015.

Canela, G.; Solano, N. (Coords.). Acesso à informação e controle social das políticas públicas. Brasília, DF: ANDI, artigo 19, 2009. Disponível em: <http://www.acessoainformacao. gov.br/central-de-conteudo/publicacoes/arquivos/acesso-a-informacao-e-controlesocial-das-politicas-publicas.pdf>. Acesso em: 12 jun. 2015.

Caregnato, R. C. A.; Mutti, R. Pesquisa qualitativa: análise de discurso versus análise de conteúdo. Texto Contexto - Enfermagem, Florianópolis: UFSC, v. 15, n. 4, p. 679-684, out./dez. 2006. Disponível em: <http://www.scielo.br/pdf/tce/v15n4/v15n4a17>. Acesso em: 10 maio 2015.

EducaçÃo Aberta. Recursos Educacionais Abertos (REA): um caderno para professores. São Paulo: 2011. Disponível em: <http://educacaoaberta.org/cadernorea/>. Acesso em: 27 dez. 2014. 
Ferreira, A. B. H. Novo dicionário Aurélio da lingua portuguesa. 3. ed. Curitiba: Positivo, 2004.

Júnior, D. P.; Amorim, J. A. Direitos autorais em EAD. In: Litto, F. M.; Formiga, M. (Orgs.). Educação a distância: o estado da arte. São Paulo: Pearson, 2012. v. 2, p. 340-343.

Lima, C. M.; Santini, R. M. Copyleft e licenças criativas de uso de informação na sociedade da informação. Ciência da Informação, Brasília: IBICT, v. 37, p. 121-128, 2008. Disponível em: <http://www.scielo.br/scielo.php?pid=S010019652008000100011\&script=sci_arttext $>$. Acesso em: 10 out. 2015.

Lôво, P. Deveres gerais de conduta nas obrigações civis. Revista Jus Navigandi, Teresina, ano 10, n. 711, 16 jun. 2005. Disponível em: <http://jus.com.br/artigos/6903/ deveres-gerais-de-conduta-nas-obrigacoes-civis\#ixzz3 $\mathrm{SxOwYCTj>.} \mathrm{Acesso} \mathrm{em:}$ 27 fev. 2015.

Marcacini, A. T. R. Propriedade intelectual e a EAD. In: Litto, F. M.; Formiga, M. (Orgs.). Educação a distância: o estado da arte. São Paulo: Pearson, 2012.v. 2, p. 333-339.

Marra, P. S. C. Visibilidade dos repositórios institucionais brasileiros: análise de diretórios internacionais de acesso aberto. Revista Eletrônica de Comunicação, Informação E̊ Inovação em Saúde, Rio de Janeiro: Fundação Oswaldo Cruz, v. 8, n. 3, p. 330-343, set. 2014. Disponível em: <http://www.reciis.icict.fiocruz.br/index.php/reciis/article/ view/930>. Acesso em: 17 fev. 2015.

Martins, R. M. Análise paradigmática do direito das obrigações: boa-fé, deveres laterais e violações positivas do contrato. Revista da EMERJ, Rio de Janeiro: Escola da Magistratura do Estado do Rio de Janeiro, v. 11, n. 44, p. 214-239, 2008.

Morato, A. C. Direitos intelectuais na internet. São Paulo: USP, 2013. (Apostila curso de Especialização e Inovação em Gestão EAD).

Müller, C. C. Recursos educacionais abertos e formação continuada de agentes públicos. In: Litto, F. M.; Formiga, M. (Orgs.). Educação a distância: o estado da arte. São Paulo: Pearson, 2012. v. 2, p. 103-115.

Nascimento, A.C.A.A. Aprendizagem por meio de repositórios digitais e virtuais. In: Litto, F. M.; Formiga, M. (Orgs.). Educação a distância: o estado da arte. São Paulo: Pearson, 2008. p. 352-357.

PARILli, R.A. Las medidas tecnológicas de protección del derecho de autor y los derechos conexos y la información eletrônica de la gestión de los derechos. In: LIPSYC, D.; PARILLI, R. A. (Orgs.). El derecho de autor y los derechos conexos ante las nuevas tecnologias: ¿Intereses compatibles o contrapuestos? Lima: Grández Gráficos SAC, 2012. p. 203-368.

Pereira, A. M. A. Uso de recursos educacionais abertos (REA) na educação superior/UAB: sonho ou realidade? 2015. 163p. Dissertação (Mestrado em Educação Matemática e Tecnológica) - Universidade Federal de Pernambuco, Recife, 2015.

Pinto, C. A. S.; Mülbert, A. L.; Spanhol, F.J., Pereira, A. T. C. Práticas para criação e distribuição de materiais didáticos para educação a distância: conteúdos abertos ou proprietários? Revista Novas Tecnologias na Educação, Porto Alegre: UFRGS, v. 9, n. 1, p. 1-9, 2011. Disponível em: <http://seer.ufrgs.br/renote/article/view/21932>. Acesso em: 27 ago. 2014. 
Rangel, F. O.; Costa, H. A.; De-Angelis, C. C.; Martins, R. L. Mediações online em cursos de educação a distância: os professores de língua portuguesa em questão. Revista Brasileira de Educação, Rio de Janeiro: ANPEd; Campinas: Autores Associados, v. 20, n. 61, p. 359-382, jun 2015. Disponível em: <http://www.scielo.br/ pdf/rbedu/v20n61/1413-2478-rbedu-20-61-0359.pdf >. Acesso em: 9 out. 2017.

Recursos Educacionais Abertos. Conceito de Recursos Educacionais Abertos. [S.1.]: REA, s/d. Disponível em: <http://www.rea.net.br/site/faq/\#a2>. Acesso em: 3 set. 2014. Rossini, C. The state and challenges of OER in Brazil: from readers to writers? 2010. Disponível em: <http://portaldoprofessor.mec.gov.br/storage/materiais/0000012013. pdf>. Acesso em: 17 fev. 2015.

Sabino, V.; Kon, F. Licenças de software livre: história e características. São Paulo: Centro de Competência em Software Livre, Universidade de São Paulo, mar. 2009. Disponível em: <http://ccsl.ime.usp.br/files/relatorio-licencas.pdf >. Acesso em: 7 jan. 2015.

Silva, E. L.; Café, L.; Catapan, A. H. Os objetos educacionais, os metadados e os repositórios na sociedade da informação. Ciência da Informação, Brasília: IBICT, v. 39, p. 93-104, 2010. Disponível em: <http://www.scielo.br/scielo.php?script=sci_arttext\& pid=S0100-19652010000300008 >. Acesso em: 9 out. 2017.

Silveira,D.T.; Córdova, F.P.A pesquisa científica. In: Gerhardt,T.E.; Silveira,D.T. (Orgs). Métodos de pesquisa. Porto Alegre: Editora da UFRGS, 2009.p.31-42. Disponível em: <https://www.lume.ufrgs.br/bitstream/handle/10183/52806/000728684. pdf?sequence=1>. Acesso em: 20 dez. 2014.

SouZa, M. A.; Mura kawa, L. S. G. Guia prático I: introdução à propriedade intelectual. São Paulo: Universidade de São Paulo, 2014. Disponível em: <http://www.inovacao. usp.br/cartilhas/PI_Cartilha.pdf>. Acesso em: 6 jan. 2015.

UNESCO - Organização das Nações Unidas para a Educação, a Ciência e a Cultura. Declaração REA de Paris. Paris: UNESCO, 2012. Disponível em: <http:// www.unesco.org/new/fileadmin/MULTIMEDIA/HQ/CI/WPFD2009/Portuguese_ Declaration.html>. Acesso em: 26 ago. 2014.

Valente, M. G. Direitos autorais como comércio internacional: desafios políticos. In: Nalini, J. R. (Org.). Propriedade intelectual em foco. 1. ed. São Paulo: Revista dos Tribunais, 2013. v. 1, p. 120-144.

\section{SOBRE A AUTORA}

Alice Aquino Zanin é mestre em odontologia legal pela Universidade de São Paulo (USP).

E-mail: alicezanin2@gmail.com 